\title{
FATORES DE ADERÊNCIA E DESISTÊNCIA DE PROGRAMAS DE MENTORIA VOLTADOS PARA SUPORTE A INICIATIVAS EMPREENDEDORAS
}

Adriano Albertin ${ }^{1}$

Patricia Viveiros De Castro Krakauer ${ }^{1}$

\footnotetext{
${ }^{1}$ Centro Universitário Campo Limpo Paulista / Unifaccamp
} 


\section{FATORES DE ADERÊNCIA E DESISTÊNCIA DE PROGRAMAS DE MENTORIA VOLTADOS PARA SUPORTE A INICIATIVAS EMPREENDEDORAS}

\section{Resumo:}

Esse artigo apresenta como problema a desistência e aderência ao programa Speed Mentoring do SEBRAE. Teve como objetivo propor ações para reforçar a aderência ao programa e identificar fatores de desistência em programas de mentoria. Trata-se de uma pesquisa exploratória, com abordagem qualitativa, sendo realizadas entrevistas semiestruturadas com três grupos de entrevistados: especialistas, participantes que concluíram o programa e os que não concluíram o programa. Como resultado apresenta o entendimento das características do programa e aponta os fatores de aderência e permanência dos participantes, de forma a propor ações voltadas para aumentar a aderência ao programa em questão. Contribui com o próprio SEBRAE que pode adequar o programa e também com outras instituições de fomento que busquem implementar programas de mentoria ao empreendedor.

Palavras-chave: Empreendedorismo. Programas de mentoria. Evasão de programas.

\section{Introdução}

Os programas de mentoria exercem um papel importante para o desenvolvimento do indivíduo aspirante a empreendedor, uma vez que a aprendizagem é fundamental para o processo de sobrevivência do negócio nascente em ambientes competitivos (BINGHAM; DAVIS, 2012; BERTOLIN; ZWICK; BRITO, 2013). Ganham força dentro das diversas organizações públicas e privadas, sendo visto como fator fundamental para apoiar e sustentar o avanço da carreira empreendedora do indivíduo quanto seu crescimento pessoal e profissional.

O programa de mentoria Speed Mentoring, oferecido pelo Serviço Brasileiro de Apoio às Micro e Pequenas Empresas de São Paulo (SEBRAE SP), dentro da Escola de Negócios, é voltado para indivíduos que querem empreender e estão em fase inicial do projeto de negócio. Trata-se de um programa de mentoria que envolve o aprendizado para indivíduos, equipes e/ou projetos nascentes, que visam potencializar uma ideia de negócio, um time e/ou empresa incipiente. Percebeu-se, contudo, ao analisar os registros do SEBRAE SP, que é alto o percentual de pessoas interessadas que não dão início ao programa ou o abandonam sem concluí-lo. Ao se observar os três últimos anos, 2016-2018, onde ocorreram 26 edições, percebe-se que dos que se inscreveram, 51,5\% não iniciaram o programa. E dos que iniciaram, 30,8\% não o concluíram.

Assim, o objetivo geral deste trabalho foi propor ações para reforçar a aderência ao programa Speed Mentoring, tendo como objetivos específicos: investigar os pontos de aderência e os de desistência específicos do programa Speed Mentoring e analisar tais pontos à luz da teoria consultada. 
O estudo, autorizado pelo SEBRAE SP, identificou fatores que podem colaborar para minimizar a desistência no programa Speed Mentoring, consequentemente, fortalecendo o empreendedor na criação de seus negócios. Contribui, assim, com o SEBRAE SP e também com outras instituições de fomento que queiram desenvolver ou aprimorar programas de mentoria voltados ao empreendedor.

\section{Referencial Teórico}

Nesta seção serão apresentados fundamentos teóricos considerados para suporte à pesquisa empírica, sendo as temáticas apresentadas: mentoria, programas de mentoria e evasão de programas. Torna-se essencial, contudo, destacar a conceituação de empreendedorismo considerada na presente pesquisa, visto ser norteadora da pesquisa e permear, inclusive, o programa em estudo.

Apesar de várias abordagens e diferentes conceitos aplicados ao fenômeno do empreendedorismo, neste artigo foi considerado o conceito de empreendedorismo voltado à criação de empresas, seguindo o utilizado nos relatórios do Global Entrepreneurship Monitor (GEM) que compreendem o empreendedorismo de negócio próprio, envolvendo a intenção de iniciar uma empresa (GEM, 2011).

Destaca-se que o conceito de empreendedorismo de negócio próprio não é recente e nem único. É, na verdade, a conceituação mais conhecida e utilizada no senso comum da população que sempre relaciona empreendedor com quem começa um negócio. Porém, na literatura, outros conceitos foram se desenvolvendo ao longo do tempo, com base em diferentes abordagens teóricas pela qual passou a temática, como por exemplo a econômica, que trata da exploração de oportunidades, riscos e incertezas; a comportamental, que busca entender o indivíduo empreendedor; e a com foco na gestão, que traz a inovação como essencial ao processo.

A despeito da importância dessas abordagens e conceitos adjacentes, este artigo, dado o contexto que o norteia, considerou a definição de empreendedorismo como um processo que envolve a criação, a identificação e a avaliação de oportunidade, numa lógica causal, sendo que empreendedor é quem está em busca da criação e desenvolvimento do próprio negócio.

\subsection{Mentoria}

A mentoria ou mentoring é instrumento antigo originário da mitologia grega (RAGINS; KRAM, 2007) na obra da "Odisséia" escrita por Homero, na qual o rei, antes de partir para a guerra de Tróia confiou a guarda de seu filho Telêmaco para um mentor, que era responsável para preparar e orientar Telêmaco para substituir o pai quando necessário, no comando das suas terras (SOUSA; RIGO, 2007; VERGARA, 2006).

Mentoria originalmente incorporou atributos masculino e feminino, transcendendo tempo, gênero e cultura. Apesar de raízes na mitologia, a mentoria possui uma relação muito forte que permeia a vida social e a relação de trabalho atual (OLIVEIRA NETO; SOUZASILVA, 2017). 
As primeiras publicações e teorias nessa temática surgem a partir de 1970 e propõe que o mentor é uma pessoa mais experiente, mais madura e pode ser um professor, um conselheiro ou um padrinho (RÉGIS et al., 2013). Opinião corroborada por Hezlett e Gibson (2007, p. 446) que mencionam que "a mentoria envolve uma intensa relação um-a-um, na qual uma pessoa mais sênior e experiente (um mentor) proporciona assistência a um colega menos experiente e mais júnior (o mentorado), de forma a elevar seu desenvolvimento pessoal e profissional". Esses autores acrescentam que a relação entre mentor e mentorado deve estar pautada em uma parceria que deve envolver o aprendizado para ambos.

Pode ser dividida, segundo Merriam (1983), em três grupos: mentoria de crescimento e desenvolvimento de adultos, com foco no desenvolvimento pessoal; a mentoria em ambiente acadêmico que consiste na orientação que é dada a nível acadêmico; e a mentoria para o trabalho (ou profissional) que ocorre no trabalho e tem por objetivo o crescimento profissional do mentorado.

Kram (1985) evoluiu esse entendimento e considera que dentro de cada grupo a mentoria ocorre em fases. Além desse entendimento, esse autor contribuiu com a pesquisa acadêmica sobre a temática ao identificar os resultados obtidos com o processo de mentoria, as funções da mesma e suas complexidades.

A mentoria tem como objetivo promover o desenvolvimento das pessoas e melhorar resultados e desempenho das empresas e organizações (KRAM, 1985). Teóricos de desenvolvimento adulto e de carreira descrevem mentoria como tendo grande potencial para melhorar o desenvolvimento dos indivíduos nos estágios iniciais e intermediários da carreira. Dalton, Thompson e Price (1977) e Hall (1976) retratam o resultado que se tem sobre relações de trabalho que contribuem para o crescimento e desenvolvimento do adulto e de sua carreira a partir da mentoria.

Sullivan (2000) sugere que as funções de mentoria podem contribuir em ambiente corporativo tanto quanto em ambiente do próprio negócio, especialmente diante de um cenário com novas relações de trabalho. Esse é o foco do presente trabalho que tem o foco em programas de mentorias que serão apresentados a seguir.

\subsection{Programa de Mentoria}

Os programas de mentoria surgiram no século XX, na década de 1970, visando a melhoraria da qualidade de trabalho nas empresas e o desenvolvimento do potencial do profissional (SANTOS, TRACTENBERG, PEREIRA, 2005), sendo, contudo, que os primeiros estudos sobre as formas de mentoring no trabalho e na carreira foram feitos por Cuerrier (2001).

Considera-se que para que haja o desenvolvimento de novos negócios é fundamental haver um ambiente que promova o suporte e incentivo ao empreendedorismo (VERSIANI; GUIMARÃES, 2003) e atualmente ter um mentor no ambiente de trabalho é muito importante (ENSHER; MURPHY, 2005). Por isso, são diversas as iniciativas de organizações públicas e privadas que oferecem programas de mentoria em incubadoras, aceleradoras, agentes e órgãos especializados. As mesmas acontecem aproximando profissionais mais experientes, oferecendo processos para o desenvolvimento tanto do empreendedor quanto do seu negócio. 
O programa Speed Mentoring, objeto de estudo deste artigo, objetiva o desenvolvimento tanto do empreendedor (a pessoa) quanto do negócio (o resultado). Destaca-se que essa é uma possibilitada relatada no estudo de Santos (2007) para programas de mentoria, como pode ser percebido no Quadro 1 que mostra além dos tipos de programas os indicadores dos mesmos.

Quadro 1: Tipos de programas de mentoring

\begin{tabular}{|c|c|c|}
\hline $\begin{array}{l}\text { Tipo de programa de } \\
\text { mentoring I }\end{array}$ & $\begin{array}{l}\text { Impactos e repercussões } \\
\text { intermediárias }\end{array}$ & Impactos e repercussōes finais \\
\hline Transição & $\begin{array}{l}\text { Número de profissionais } \\
\text { alocados no mercado de } \\
\text { trabalho }\end{array}$ & $\begin{array}{l}\text { Número das participações em um } \\
\text { processo completo de recrutamento, da } \\
\text { entrevista à contratação. }\end{array}$ \\
\hline Carreira & $\begin{array}{l}\text { Número de promoções } \\
\text { atingidas pelo empregado }\end{array}$ & $\begin{array}{l}\text { Redução nos índices de rotatividade e de } \\
\text { satisfação individual no trabalho }\end{array}$ \\
\hline Sucessão & $\begin{array}{l}\text { Número de candidatos } \\
\text { identificados pela organização } \\
\text { com potencial para gerência }\end{array}$ & $\begin{array}{c}\text { Número de empregados promovidos a } \\
\text { cargo gerencial através de recrutamento } \\
\text { interno e externo }\end{array}$ \\
\hline Empreendedorismo & $\begin{array}{l}\text { Número de empresas de } \\
\text { pequeno porte que } \\
\text { alavancaram o seu negócio }\end{array}$ & $\begin{array}{l}\text { Número dos negócios que experimentaram } \\
\text { crescimento de faturamento. Número de } \\
\text { postos de trabalho criados. }\end{array}$ \\
\hline
\end{tabular}

Fonte: SANTOS (2007, p. 260).

Tanto os teóricos de desenvolvimento adulto quanto os de carreira descreveram o grande potencial para melhorar o desenvolvimento dos indivíduos nos estágios iniciais e intermediários da carreira (HALL, 1976; DALTON, THOMPSON, PRICE, 1977), com isso, os programas de mentoria vem sendo implantados e valorizados nas incubadoras e aceleradoras de empresas, tendo em vista mudança de comportamento e avanço no processo de ensino aprendizagem. No entanto, pouco são os resultados empíricos apresentados em trabalhos científicos a respeito desse processo de intervenção (RÉGIS, DIAS, 2006).

No atual contexto, um empreendedor não consegue fazer tudo sozinho e necessita de apoio e sustentação de profissionais mais experientes naquele setor ou área de atuação, que proponha desafios e ajude-o a crescer e a aprendizagem é fundamental para processo de sobrevivência dos negócios nascentes em ambientes competitivos (BINGHAM, DAVIS, 2012; BERTOLIN et al., 2013).

O foco do desenvolvimento das competências profissionais dos indivíduos não está nas suas reais necessidades, as organizações formatam programas e direciona os mesmos aos empreendedores, profissionais e indivíduos. São estratégias utilizadas pelas instituições de fomento e organizações em programa de mentoria ou programa de desenvolvimento profissional, na busca do desenvolvimento do trabalhador e do empreendedor, de modo a prepará-lo para o mercado (FREIRE et al., 2017; CASTRO et al., 2017), buscando atender um maior número possível de interessados. 
Apesar desse interesse, a evasão é uma realidade em programas de mentoria, como será apresentado a seguir.

\subsection{Evasão de Programas}

Em organizações do setor educacional, uma das maiores preocupações é a permanência dos participantes até o final do programa/curso. Como instrumento para tomar decisões que amenizem esse problema, torna-se necessário conhecer os motivos de evasão. Esse problema impacta toda a sociedade, pois envolve não apenas as instituições de ensino e os participantes que deixam os ambientes educacionais, mas também o mercado que tem dificuldades para encontrar mão-de-obra capacitada (SILVA, 2016).

O indivíduo evadido não chega ao final do programa e não terá acesso a todo o conhecimento e práticas propostas, não adquirindo as habilidades e aprendizagens necessárias para o pleno desenvolvimento das tarefas impostas à atividade profissional e empreendedora, $\mathrm{o}$ que poderá limitar suas oportunidades.

As barreiras podem ser definidas como situações que evitam, impedem ou interrompem a aprendizagem ou encerram este processo prematuramente, como por exemplo, restrições de recursos (finanças, tempo, conhecimento). Já os facilitadores são fatores que auxiliam os aprendizes a adquirir novos conhecimentos e habilidades, sendo capazes de motivar, sustentar e/ou melhorar a aprendizagem (MARTINS, 2012).

Crouse et al. (2011) constataram que compartilhadas ou específicas as barreiras/ facilitadores de aprendizagem existem entre diversas categorias profissionais e abrangem diversas variáveis que interferem na ocorrência da desistência/persistência. Entre elas os autores mencionam: o desempenho do tutor e questões relativas à qualidade do trabalho do mesmo; as características peculiares do desenho instrucional como interface gráfica e o ambiente de aprendizagem; a disponibilidade de apoio técnico e psicossocial fornecido pelos pares; e organização e facilidade de uso da tecnologia.

Segundo Souza e Zerbini (2019) a reação dos indivíduos é importante na avaliação das ações educativas, pois reflete a satisfação do participante com o ritmo, a forma, organização do programa e o aprendizado. Ou seja, avaliar a satisfação dos indivíduos é fundamental para programas educacionais. Apesar desse estudo não ter o foco em programas de mentoria, ele traz luz ao entendimento de que os mesmos precisam ser avaliados pela ótica de seus participantes, foco da atual pesquisa.

Finalizando o referencial, destaca-se que não foram encontrados estudos específicos sobre a evasão em programas de mentoria. Foi feita uma extensa busca no Google Scholar no dia 10/04/2019, utilizando-se diferentes palavras-chaves, tanto em português quanto em inglês e os estudos encontrados não possuíam o foco em programas de mentoria. Tal resultado por um lado dificulta o arcabouço teórico do estudo, mas, por outro, abre novas possibilidades de pesquisa. 


\section{Método}

Trata de uma pesquisa com alegação do conhecimento reivindicatória participante, orientada para mudança com caráter e natureza exploratória, com abordagem qualitativa e método de levantamento de dados qualitativos, que ofereceu condições de proporcionar entendimento e respostas para o problema de pesquisa e atingir os objetivos da atual pesquisa. Tais escolhas metodológicas consideraram a particularidade de se estar trabalhando um programa específico e buscar respostas para o mesmo, buscando entender os porquês da desistência e da aderência.

Como método optou-se pela pesquisa de campo com levantamento de dados qualitativo, utilizando-se como técnica de coleta de dados a entrevistas estruturada. Creswell (2007) argumenta que as entrevistas representam uma das técnicas mais comuns para esse tipo de método, por serem uma fonte direta de informação e permitem a percepção dos pontos de vista e experiências dos entrevistados.

Optou-se por investigar três grupos distintos: (i) os especialistas em programas de mentoria; (ii) os inscritos no programa Speed Mentoring da Escola de Negócios Sebrae SP que não o concluíram; e (iii) os que se inscreveram, iniciaram e concluíram o programa em questão.

Foram entrevistados cinco especialistas em mentoria (Grupo A), cinco entrevistados dentre os que se inscreveram e não concluíram (Grupo B) e dez entrevistados dentre os que se inscreveram, iniciaram e concluíram o programa (Grupo C). Destaca-se que foram enviados 20 convites para indivíduos pertencentes ao Grupo B e 30 convites para o Grupo C, mas o Grupo $\mathrm{B}$ teve um menor retorno no que concerne o aceite em participar da pesquisa. Todos foram selecionados na base de dados do SEBRAE SP. Já para o Grupo A foram encaminhados 5 convites, por ecessibilidade, e todos foram aceitos.

Como procedimento de análise de dados foi utilizada a análise de conteúdo. Para Bardin (1977) a análise de conteúdo, enquanto método, trata de um conjunto de técnicas de análise envolvendo as comunicações através de entrevistas presenciais e remotas por canais digitais, tendo como objetivo a descrição do conteúdo das mensagens.

Após a realização das entrevistas, as mesmas foram transcritas de modo a elaborar um quadro analítico que facilitou a análise dos achados e a definição das categorias, como pode ser percebido no Quadro 2.

Quadro 2: Especificação de Categorias de Análise - Grupos A, B e C

\begin{tabular}{|l|c|c|c|}
\hline \multicolumn{1}{|c|}{ CATEGORIAS DE ANÁLISE } & Grupo A & Grupo B & Grupo C \\
\hline $\begin{array}{l}\text { Expectativas ao se inscrever no programa } \\
\text { Speed Mentoring }\end{array}$ & $\mathrm{X}$ & $\mathrm{X}$ & $\mathrm{X}$ \\
\hline Fatores de desistência & $\mathrm{X}$ & $\mathrm{X}$ & $\mathrm{X}$ \\
\hline Fatores de aderência & $\mathrm{X}$ & $\mathrm{X}$ & $\mathrm{X}$ \\
\hline
\end{tabular}




\begin{tabular}{|l|c|c|c|}
\hline O que é necessário ter no programa & $\mathbf{X}$ & $\mathbf{X}$ & $\mathbf{X}$ \\
\hline O que não deve ter no programa & $\mathbf{X}$ & & $\mathbf{X}$ \\
\hline Expectativas não atendidas & & $\mathbf{X}$ & \\
\hline Por que desistiu do Programa & & $\mathbf{X}$ & $\mathbf{X}$ \\
\hline Sugestões de melhoria & & & \\
\hline
\end{tabular}

Fonte: Elaborado pelos autores

\section{Resultados}

Com a pesquisa teórica e empírica percebeu-se que a evasão configura prejuízo para a instituição de ensino ou mesmo a de fomento, uma vez que a vaga perdida não será reposta. Além disso, recursos como espaço físico, instrutores e equipe pedagógica, são mantidos para aquela turma, independentemente da quantidade de alunos. Além disso, compreendeu-se que é essencial a realização de uma pesquisa de satisfação constante com os mentorados, de forma que a instituição patrocinadora possa adequar com maior rapidez o programa às necessidades do seu público.

De modo a atender aos objetivos da pesquisa, as categorias foram analisadas individualmente e posteriormente passaram a constituir o corpus da pesquisa ao serem tratadas de forma consolidada (Quadro 3).

\section{Quadro 3: Resultados consolidados}

\begin{tabular}{|l|l|l|}
\hline Categorias & \multicolumn{1}{|c|}{ Resultado consolidado } & \multicolumn{1}{|c|}{ Autores } \\
\hline & $\begin{array}{l}\text { Os respondentes buscam adquirir o } \\
\text { conhecimento, experiência e entendimento do } \\
\text { mercado, mais criatividade, ideias } \\
\text { empreendedoras e mais contatos com } \\
\text { profissionais da área (network). }\end{array}$ & $\begin{array}{l}\text { Kram (1985); Dalton, } \\
\text { Hall (1976); Ragins e } \\
\text { Kram (2007); Bingham e } \\
\text { Davis (2012); Bertolin et } \\
\text { al. (2013) }\end{array}$ \\
\hline $\begin{array}{l}\text { Fatores de } \\
\text { Desistência }\end{array}$ & $\begin{array}{l}\text { Falta de tempo, reciprocidade, prioridade, } \\
\text { integração, sintonia, mentores que não } \\
\text { respondem aom } \\
\text { questionamentos; falta propósito e diferencial, } \\
\text { problemas pessoais, a falta de um projeto e de } \\
\text { ideias e o tipo de curso ofertado. }\end{array}$ & \multicolumn{1}{|c|}{ Silva (2016) } \\
\hline $\begin{array}{l}\text { Fatores de } \\
\text { Aderência }\end{array}$ & $\begin{array}{l}\text { Geração de valores, conhecimento, conexão } \\
\text { entre mentor e mentorado, exemplo e } \\
\text { experiência do mentor, empatia do mentor com } \\
\text { o negócio do mentorado, elaboração do plano } \\
\text { de negócios, comprometimento, o nome } \\
\text { SEBRAE, o conhecimento adquirido na } \\
\text { prática e o contato com outros profissionais } \\
\text { que conhecem o mercado (network). }\end{array}$ & $\begin{array}{l}\text { (1985); Souza e Zerbini } \\
\text { (2019) }\end{array}$ \\
\hline
\end{tabular}




\begin{tabular}{|c|c|c|}
\hline $\begin{array}{l}\text { O que é } \\
\text { necessário } \\
\text { ter no } \\
\text { programa }\end{array}$ & $\begin{array}{l}\text { Um programa estruturado, com o engajamento } \\
\text { de pessoas. Deve-se ter cronograma de } \\
\text { atividades com análise e diagnóstico do } \\
\text { negócio. A mentoria precisa ser mais focada, } \\
\text { objetiva, alinhada e com valores } \\
\text { compartilhados. Profissionais com experiência } \\
\text { e conhecimentos técnicos, uma agenda bem } \\
\text { definida, respeitando a necessidade do } \\
\text { empresário e a seleção correta de mentor e } \\
\text { mentorado. }\end{array}$ & $\begin{array}{l}\text { Sullivan (2000); Kram } \\
\text { (2007); Ensher, Heun e } \\
\text { Blanchard (2003); } \\
\text { Hamilton e Scandura } \\
\text { (2003); Single e Muller } \\
\text { (2001); Ensher e Murphy } \\
\text { (2005); Kram (1988); } \\
\text { Mezias e Scandura } \\
\text { (2005); Kram (1988) }\end{array}$ \\
\hline $\begin{array}{l}\text { O que não } \\
\text { deve ocorrer } \\
\text { no } \\
\text { programa }\end{array}$ & $\begin{array}{l}\text { Não deve haver uma mentoria em grupo, a falta } \\
\text { de flexibilidade e atividades alheias ao } \\
\text { programa, (como a venda de consultoria), pois } \\
\text { isso tira o foco do programa e do } \\
\text { empreendedor. }\end{array}$ & $\begin{array}{llrl}\text { Freire } & \text { et } & \text { al. } & \text { (2017); } \\
\text { Castro; } & \text { et al. } & (2017) ; \\
\text { Kishore } & (2013) ; & \text { Martins } \\
(2012) & & \end{array}$ \\
\hline $\begin{array}{l}\text { Expectativas } \\
\text { não } \\
\text { atendidas }\end{array}$ & $\begin{array}{l}\text { Não sentiram que as suas expectativas foram } \\
\text { atendidas em relação ao aprendizado e } \\
\text { conhecimento para o negócio que estavam } \\
\text { desenvolvendo. }\end{array}$ & $\begin{array}{l}\text { Régis e Dias (2006); } \\
\text { Kram (1985); Higgins e } \\
\text { Kram (2001) }\end{array}$ \\
\hline $\begin{array}{l}\text { Motivos de } \\
\text { desistência }\end{array}$ & $\begin{array}{l}\text { O programa era mais voltado para às startups } \\
\text { em fase inicial, não havia prioridade e não } \\
\text { sabiam ao certo a sua importância. }\end{array}$ & $\begin{array}{l}\text { Bingham; Davis (2012); } \\
\text { Bertolin et al. (2013) }\end{array}$ \\
\hline $\begin{array}{l}\text { Sugestões de } \\
\text { melhoria }\end{array}$ & $\begin{array}{l}\text { Divulgar e qualificar o programa e seus } \\
\text { conteúdos, podiam ministrados em blocos para } \\
\text { que o empreendedor pudesse escolher; ter mais } \\
\text { atividades práticas, ser mais focado no negócio } \\
\text { dos empreendedores, feedback antes da } \\
\text { conclusão do programa, tempo maior e maior } \\
\text { disponibilização de materiais de leitura e } \\
\text { acompanhamento após o final da mentoria }\end{array}$ & $\begin{array}{l}\text { Higgins e Thomas (2001); } \\
\text { Santos (2007) }\end{array}$ \\
\hline
\end{tabular}

Fonte: Elaborado pelos autores

Ao observar no Quadro 3 os aspectos mencionados pelos entrevistados do Grupo B e C sobre a expectativa ao se inscreverem no programa Speed Mentoring percebe-se que tais achados corroboram com Kram (1985), Dalton, Thompson e Price (1977) e Hall (1976) que relacionam as mentorias com a promoção do desenvolvimento pessoal e com a melhoria de resultados organizacionais.

Os fatores de desistência listados pelos respondentes são compatíveis com os mencionados por Silva (2016) e os de aderência retratam a necessidade da experiência do mentor, aderente com a pesquisa de Hezlett e Gibson (2007) que apresenta os mentores como indivíduos experientes e comprometidos no desenvolvimento e ajuda aos mentorados.

Com relação a categoria 'que é necessário ter no programa' destaca-se a necessidade de maior estruturação do mesmo, compatível com os estudos de Kram (1985). Sobre 'o que não deve ter' mencionamos a fala dos entrevistados acerca da mentoria grupal, o que vai ao encontro de autores que a definem como possível no contato um-a-um. Alguns dos entrevistados mencionaram também não perceber que sua expectativa sobre o aprendizado específico do seu negócio tenha sido atendida, visto o programa ter o foco em startups, o que é mencionado como o principal motivo de desistência. 
Várias foram as sugestões de melhorias que podem ser visualizadas no Quadro 3 e elas foram o pilar para a elaboração de uma proposta de ações (Quadro 4), sendo esse o objetivo geral da presente pesquisa.

Quadro 4: Ações propostas para reforçar o programa Speed Mentoring

\begin{tabular}{|c|c|c|}
\hline Item & Ações apontadas pelos entrevistados & Ações propostas \\
\hline Programa & $\begin{array}{l}\text { - A geração de valores } \\
\text { - Alta aquisição de conhecimento, não só } \\
\text { teórico, mas principalmente prático } \\
\text { - A grade do curso com o conteúdo atualizado } \\
\text { - Comprometimento com o programa } \\
\text { - A percepção clara de valor e de resultados } \\
\text { - Um plano de negócios } \\
\text { - Estratégias para atingir o objetivo do curso }\end{array}$ & $\begin{array}{l}\text { - Identificar as expectativas do mentorado em } \\
\text { relação ao processo, bem como, suas } \\
\text { necessidades de desenvolvimento } \\
\text { - Reavaliar a metodologia e o programa do curso } \\
\text { de forma contínua } \\
\text { - Elaborar cronograma de ensino } \\
\text { - Utilizar projetos interdisciplinares } \\
\text { - Expandir o leque de habilidades e temas a } \\
\text { serem trabalhados no processo de mentoria } \\
\text { - Avaliar a reação e aprendizado dos } \\
\text { participantes } \\
\text { - Darfeedback aos participantes }\end{array}$ \\
\hline $\begin{array}{c}\text { Mentor/ } \\
\text { Mentorado }\end{array}$ & $\begin{array}{l}\text { - A conexão entre mentor e mentorado } \\
\text { - O exemplo do mentor } \\
\text { - O conhecimento e empatia do mentor com } \\
\text { o negócio do mentorado } \\
\text {-A experiência dos mentores } \\
\text { - O contato com outros profissionais que } \\
\text { conhecem o mercado, o networking. }\end{array}$ & $\begin{array}{l}\text { - Reconhecimento das mútuas capacidades e do } \\
\text { que um tem a oferecer ao outro (mentor e } \\
\text { mentorado). } \\
\text { - Estimular os mentores a desenvolverem seu } \\
\text { pitch e plano de negócios } \\
\text { - Investir em capacitação dos mentores } \\
\text { - Reduzir o número de mentores por mentoria } \\
\text { - Promover rodadas de palestras e encontros } \\
\text { (eventos) com profissionais da área } \\
\text { - Promover reuniões com representantes de } \\
\text { entidades, para trocas de experiências, ideias e } \\
\text { mais comprometimento } \\
\text { - Organizar grupos de estudo }\end{array}$ \\
\hline $\begin{array}{c}\text { Instituição } \\
\text { de ensino }\end{array}$ & Escola de Negócios Sebrae SP & $\begin{array}{l}\text { - Investir em recursos multimídia } \\
\text { - Utilizar tecnologia como facilitadora da } \\
\text { aprendizagem } \\
\text { - Organizar e difundir acervo bibliográfico } \\
\text { - Incentivar a pesquisa }\end{array}$ \\
\hline
\end{tabular}

Fonte: elaborado pelos autores 


\section{Considerações Finais}

Os programas de mentoria entraram no mundo dos negócios com o objetivo de melhorar a qualidade de trabalho nas empresas e criarem condições para que as pessoas pudessem desenvolver o seu potencial. Eles vêm sendo implantados e valorizados nas incubadoras e aceleradoras de empresas, tendo em vista mudança de comportamento e avanço no processo de ensino aprendizagem. No entanto, pouco são os conhecimentos científicos a respeito desse processo de intervenção e há uma dificuldade no uso do termo mentoring que muitas vezes não está adequado, ao que se tem na literatura. Percebeu-se, assim, uma lacuna teórica e uma prática, no que tange os números apresentados pelo SEBRAE SP acerca dos resultados alcançados com o programa Speed Mentoring.

Após a realização da pesquisa empírica, pode-se perceber que vários são os fatores de desistência e de aderência e que os mesmos corroboram com os existentes na literatura consultada. Muitos voltam-se a relação existente entre mentor e mentorado, o que mostra a importância de tal conexão, possibilitando que ações fossem propostas no sentido de melhor selecionar os mentores para cada mentorado, formando um match mais assertivo.

Percebeu-se que a relação entre mentor e mentorado deve ter como base uma parceria que deve envolver o aprendizado de ambos e ser mais duradoura de modo a formar uma rede de relacionamento, promovendo o desenvolvimento das pessoas e possibilitando a melhoria do desempenho das empresas.

Ao finalizar a pesquisa, conclui-se que parte dos empreendedores que se inscrevem no programa Speed Mentoring iniciam e não concluem todas as etapas do curso, o que faz com que o empreendedor não adquira todo o conhecimento proposto no planejamento do programa. Além disso a evasão configura prejuízo para a instituição de fomento, uma vez que a vaga não será reposta quando o empreendedor inicia e não conclui o programa.

A pesquisa realizada apresentou limitações metodológicas, especialmente pela amostra ter sido selecionada por acessibilidade. Poderia se pensar em um estudo futuro que considerasse convidar todos os participantes das edições passadas, ou mesmo realizar um estudo quantitativo que possa trazer dados conclusivos. A atual pesquisa tinha por objetivo a profundidade e o levantamento dos fatores que podem servir como alicerce para a elaboração de um questionário a ser aplicado em uma pesquisa futura com abordagem quantitativa.

Uma outra limitação diz respeito ao referencial teórico, pois, apesar do esforço de busca, poucos trabalhos foram encontrados sobre a mesma temática. Mas gera também a possibilidade de estudos futuros, sejam bibliométricos, sejam teóricos, que possam trazer luz sobre uma temática atual e que contribui com o ecossistema empreendedor.

\section{Referências}

ABBAD, G.; CARVALHO, R.S.; ZERBINI, T. Evasão em curso via internet: explorando variáveis explicativas. RAE eletrônica., São Paulo, v. 5, n. 2, Dec. 2006. 
BARDIN, L. Análise de conteúdo. Lisboa: Edições 70, 1977.

BERNHOEFT, R.E.A. Mentoria: abrindo horizontes, superando limites, construindo caminhos. 2a . ed. São Paulo: Editora Gente, 2001.

BERTOLIN, R.V.; ZWICK, E.; BRITO, M.J. Aprendizagem organizacional sócio prática no serviço público: um estudo de caso interpretativo. Revista de Administração Pública, Rio de Janeiro, v. 47, n. 2, p. 493-513, Apr. 2013.

BIEREMA, L. L.; MERRIAM, S. B. E-mentoring: Using computer-mediated communication to enhance the mentoring process. Innovative Higher Education, 26(3), 211227, 2002.

BINGHAM, C.B.; DAVIS, J.P. Learning Sequences: Their Existence, Effect, and Evolution. Academy of Management. Journal. Briarcliff Manor, v.55, n. 3, p. 611-641, 2012.

BOZIONELOS, N. The relationship between disposition and career success: A British study. Journal of Occupational and Organizational Psychology, v. 77, n. 3, 403-420, 2004.

CASTRO, T. R.; SILVA, V. L.; FERNANDES, A. C.; JUNKES, V. H. O potencial empreendedor do curso de Engenharia de Produção: o caso da UNESPAR. Anais XI Encontro de Engenharia de Produção Agroindustrial. Campo Mourão, Paraná, 2017.

CRESWELL, J. Projeto de pesquisa: métodos qualitativo, quantitativo e misto. 2. ed. Porto Alegre: Bookman, 2007.

CROUSE, P.; DOYLE, W.; YOUNG, J. D. Workplace learning strategies, barriers, facilitators and outcomes: A qualitative study among human resource management practitioners. Human Resource Development International, 14(1), 39-55. 2011.

CUERRIER, C. Mentoring and the world of work. Charlesbourg, QC: Edition de la Fondation, 2001.

DALTON, G. W.; THOMPSON, P. H.; PRICE, R. L. The four stages of professional careers: A new look at performance by professionals. Organizational Dynamics, v. 6, n.1, p.19-42, 1977.

ENDEAVOR BRASIL. Somos uma organização global sem fins lucrativos. Disponível em: https://endeavor.org.br/quem-somos/ Acesso em: 20/10/2018.

\section{Como Elaborar um Pitch (quase) perfeito.} https://endeavor.org.br/dinheiro/como-elaborar-um-pitch-quase-perfeito/. Acesso em: $18 / 06 / 2019$. 
ENSHER, E. A.; HEUN, C. BLANCHARD, A. Online mentoring and computermediated communication: new directions in research. Journal of Vocational Behavior, Atlanta, v. 63, n. 2, p. 264-288, 2003.

ENSHER, E.A.; MURPHY, S.E. Power mentoring: how successful mentors and protégés get the most out of their relationships. San Francisco: Jossey-Bass, 2005.

FISHER, G. Effectuation, Causation and Bricolagem: A behavioral comparison of emerging theories in entrepreneurship research. Entrepreneurship Theory and Practice, p. 1019-1051, 2012.

FORGERINI, F.; MATOS, P.L.; FERREIRA, M.C. Projeto Padrinho: Resultados de um projeto de Educação Tutorial no Ensino de Ciências em Nível Superior. Revista Ciência em Extensão, 13(3), 77-86, 2017.

FREIRE, C.; MARUYAMA, F.; POLLI, M. Inovação e empreendedorismo: políticas públicas e ações privadas. Novos estudos, CEBRAP, São Paulo, v. 36. n.3, p. 51 -76, 2017.

GARRISON, D. Apostiles of Culture: The Public Librarian and American Society, New York: Free Press. 1876-1920. 1979.

GIL, A.C. Como elaborar projetos de pesquisa. 4. ed. São Paulo: Atlas, 2007.

GOLDENBERG, M. A arte de pesquisar. $13^{a}$ edição revisada. Rio de Janeiro: Record, 1997.

GLOBAL ENTREPRENEURSHIP MONITOR. GEM Empreendedorismo no Brasil: Coordenação de Simara Maria de Souza Silveira Greco; autores: Andreassi, T. [et al] -Curitiba: IBQP, 2011.

HALL, E.T. Beyond Culture. New York: Doubleday. 1976.

HAMILTON, B.A.; SCANDURA, T.A. E-mentoring: implications for organizational learning and development in a wired world. Organizational Dynamics v. 31, n .4. p. 388402, 2003.

HEZLETT, S.A.; GIBSON, S.K. Linking mentoring and social capital: implications for careers and organization development. Advances In Developing Human Resources, [S.1.], n. 9, p.384-412, 2007.

HIGGINS, M. C. The more, the merrier? Multiple developmental relationships and work satistfction. Journal of Management Development. 19. 277-296. 2000. 
HIGGINS, M. C.; KRAM, K. E. Reconceptualizing mentoring at work: A developmental network perspective. The Academy of Management Review. 2001.

HIGGINS, M.C; THOMAS, D.A. Constellations and careers: toward understanding the effects of multiple developmental relationships. Journal of organizational behavior v.22, n.3. 2001.

KISHORE, A. Mentor: o outro lado da relação de mentoring. Tese de Doutorado. São Paulo: Universidade de São Paulo. USP. Faculdade de Economia, Administração e Contabilidade. 2013.

KNOUSE, S. Virtual Mentors: Mentoring on the Internet. Journal of Employment Counseling. v.38, n.4, p.162-169. Dec. 2001.

KNOUSE, S. B. WEBB, S. C. Unique types of mentoring for diverse groups in the military. Review of Buisness, 48-52, 2000.

KRAM, K.E. Mentoring at work: development relationships in organizational life. Lanham: University Press of America, 1985.

Mentoring at work: developmental relationships in organizational life. Lanham: University Press of America, 1988.

KRAM, K.E.; ISABELLA, L.A. Mentoring alternatives: the roles of peer relationships in career development. Academy of Management Journal. Vol. 28, No. 1 (Mar., 1985), pp. 110-132.

LOTT, A.C.O.; FREITAS, A.S.; FERREIRA, J.B.; LOTT, Y.M. Persistência e Evasão na Educação a Distância: Examinando Fatores Explicativos. Revista Eletrônica de Ciência Administrativa, [S.1.], v. 17, n. 2, p. 149-171, maio de 2018.

MARTINS, L. B. Aprendizagem em ações educacionais a distância: Fatores influentes no desempenho acadêmico de universitários. Dissertação de Mestrado. Faculdade de Filosofia, Ciências e Letras de Ribeirão Preto, Ribeirão Preto: Universidade de São Paulo, 2012.

McCLELLAND, D. C. Managing motivation to expand human freedom. American Psychologist. v. 33, n. 3, p., 201-210, 1978.

MEZIAS, J.M; SCANDURA, T.A. A needs-driven approach to expatriate adjustment and career development: A multiple mentoring perspective. Journal of international business studies. v. 36, n.5, p.519-538, 2005.

MERRIAM, S. Mentors and Protégés: A Critical Review of the Literature. Adult Education Quarterly - Adult Educ Quart. 33. 161-173, 1983. 
OLIVEIRA NETO, C.C.; SOUZA-SILVA, J.C. Aprendizagem, mentoria e cultura organizacional de aprendizagem: o estudo do caso da performance consultoria e auditoria. Read. Rev. eletrôn. adm. Porto Alegre, v. 23, n. spe, p. 60-92, dez. 2017. Disponível em http://www.scielo.br/scielo.php?script=sci_arttext\&pid=S141323112017000400060\&lng=pt \&nrm=iso. Acesso em: 19/10/2018.

O'NEILL, D. K.; HARRIS, J. B. Bridging the perspectives and developmental needs of all participants in curriculum-based telementoring programs. Journal of Research on Technology in Education, v.37, n.2, p. 111-128, 2004.

OTA, M.A; JUNIOR, C.F.A; BARROS, D. Estilos de aprendizagem em ambientes virtuais: cenários de investigação na educação superior. Educação, Formação \& Tecnologias (janeiro-junho, 2017), 10 (1), 47-58.

PARKS, M.R.; ROBERTS, L.D. Making Moosic: The development of personal relationships on line and a comparison to their offline counterparts, Journal of Social and Personal Relationships, 15, 517-537. 1998.

PIMENTEL, F. S. C.; MERCADO, L.P.L.; FREITAS, M.A.S.; OLIVEIRA, C.L.A.P. Ações de extensão na educação a distância: a experiência de implementação numa universidade pública. Revista de Educação à distância, v.5, n.3, p.641-655, 2018.

RAGINS, B. R.; KRAM, K. E. The roots and meaning of mentoring. In: RAGINS, B.R.; KRAM, K. E. The handbook of mentoring at work - theory, research, and practice. Thousand Oaks, CA: SAGE Publications, 2007.

RÉGIS, H.P; DIAS, S.M.R.C. Redes informais de mentoria no ambiente de incubadoras de base tecnológica: o apoio ao desenvolvimento da carreira empreendedora. Journal of Technology Management \& Innovation, December, 2006, ano, 1, Volume 1, Issue 5, Research Group Santiago, Chile, pp. 40-52, 2006.

REGIS, H.P.; BASTOS, A.V.B.; DIAS, S.M.R.C.; MELO, P.T.N.B. Redes de mentoria: mapeando as concepções nas incubadoras de base tecnológica do Recife. Rev. Psicol., Organ. Trab., Florianópolis, v. 13, n. 3, p. 241-255, dez. 2013.

SANTOS, A. R. Metodologia científica: a construção do conhecimento. 4. ed. Rio de Janeiro: DP\&A. 2001.

SANTOS, E.O.; TRACTENBERG, L.; PEREIRA, M. Mentoria: a formação inicial e continuada dos professores-tutores no programa FGV Online. pp. 1-10. Maio de 2005. Disponível em: http://www.abed.org.br/congresso2005/por/pdf/144tcc5.pdf. Acesso em: $30 / 04 / 2019$ 
SANTOS, N.M.B.F. Programas de mentoring: aprendendo com a realidade canadense. Revista Interfaces Brasil - Canadá, Rio Grande, n.7, p.351-365. 2007.

SCANDURA, T. A. Dysfunctional mentoring relationships and outcomes. Journal of Management, 1998.

Mentorship and Career Mobility: An Empirical Investigation. Journal of Organizational Behavior. v. 13, n. 2, Mar., 1992, pp. 169-174.

SCHEIN, E, H. Identidade profissional: como ajustar suas inclinações a suas opções de trabalho. Tradução de Margarida D. Black. São Paulo: Nobel, 1996.

SILVA. I. P.; SILVA, E.V.; PAMPLONA, M.M.; SANTOS, R. J.A.M.A. Redes de Cooperação: uma Experiência com E-Learning na Área de Tecnologias e Gestão no IFPE Campus Recife. Revista Caravana - Diálogos entre Extensão e Sociedade, v.3, n.2, p.105117, 2018.

SILVA, M. J. D. As causas da evasão escolar: estudo de caso de uma escola pública de Ensino Fundamental no município de Acará-PA. InterEspaço: Revista de Geografia e Interdisciplinaridade, v. 2, n. 6, p. 367-378, 2016.

SINGLE, P.B.; MULLER, C.B. When email and mentoring unite: The implementation of a nationwide electronic mentoring program: MentorNet, the national electronic industrial mentoring network for women in engineering and science. In L.K. Stromei (Ed.), Creating mentoring and coaching programmes, 107-122. Alexandria, VA: ASTD. 2001.

SOUSA, A.A; ZERBINI, T. Learning predictors in a distance program: a study with public healthcare providers. Temas psicol., Ribeirão Preto, v.27, n.1, p.11-23, mar. 2019.

SOUSA, D.C.; RIGO, A.S. Mentoria na perspectiva daquele que aprende: o caso de uma empresa multinacional de consultoria. Universidade Federal de Pernambuco. Disponível em: http://sistema.semead.com.br/9semead/resultado_semead/trabalhosPDF/128.pdf. Acesso em 30/04/2019.

SULLIVAN, R. Aprendizagem empreendedora e mentoring. Revista Internacional de Comportamento Empreendedor e Pesquisa. v. 6, Edição: 3. pp.160-175, 2000.

Entrepreneurial learning and mentoring. International Journal of Entrepreneurial Behaviour \& Research, vol. 6 n.3. University Press, 2000, 1355-2554.

VALE, G. M. V. Empreendedor: origens, concepções teóricas, dispersão e integração. Revista de Administração Contemporânea, Rio de Janeiro, v. 18, n. 6, p. 874-891, 2014.

VERGARA, S.C. Gestão de pessoas. 5 ed. São Paulo: Atlas, 2006. 
VERSIANI, A.; GUIMARAES, L. Aprendendo a estruturar um novo negócio - o papel das incubadoras na constituição das pequenas empresas de base tecnológica. In: Encontro da Associação Nacional de Pós-Graduação e Pesquisa em Administração, Atibaia. Anais... Atibaia [s.n.t.], 2003.

XAVIER, N. R.; GUIMARÃES, D. M. L. P. Dificuldades não esperadas na primeira tutoria: uma visão da mentoria. Revista FGV Online, v. 4, n. 1, p. 59-71, 2014. 